\title{
Ternary and quaternary Cr or Ga-containing ex-LDH catalysts - influence of the additional oxides onto the microstructure and activity of $\mathrm{Cu} / \mathrm{ZnAl}_{2} \mathrm{O}_{4}$ catalysts
}

\author{
Stefanie Kühl ${ }^{a}$, Julia Schumann ${ }^{a}$, Igor Kasatkin $^{a}$, Michael Hävecker $^{a}$, \\ Robert Schlögl ${ }^{a, b}$, Malte Behrens ${ }^{a, c *}$ \\ ${ }^{a}$ Fritz-Haber-Institut der Max-Planck-Gesellschaft, Department of Inorganic Chemistry, Faradayweg 4-6, 14195 Berlin, \\ Germany; ${ }^{b}$ Max-Planck-Institute for Chemical Energy Conversion, Heterogeneous Reactions Department, Stiftstr. 34-36, \\ 45470 Mülheim an der Ruhr, Germany; ${ }^{c}$ University of Duisburg-Essen, Faculty of Chemistry and Center for \\ Nanointegration Duisburg-Essen (CENIDE), Universitätsstr. 5-7, 45141 Essen, Germany \\ *malte.behrens@uni-due.de, phone:+49 201 183-3684
}

The stepwise substitution of $\mathrm{Al}$ by $\mathrm{Cr}$ and Ga leads to quaternary $\mathrm{LDH}$ precursors for $\mathrm{Cu} / \mathrm{ZnM}_{2} \mathrm{O}_{4}(\mathrm{M}=\mathrm{Al}, \mathrm{Ga}, \mathrm{Cr})$ catalysts. With the substitution of $\mathrm{Al}$ by $\mathrm{Cr}$ the interaction of the $\mathrm{Cu}$ phase with the oxide matrix is gradually weakened, which is caused by the participation of the chromium oxide phase in the redox processes during catalyst preparation. Such reactive Cr oxide matrix is less efficient than the inert Al oxide matrix in stabilizing the special microstructure of $\mathrm{Cu} / \mathrm{ZnM}_{2} \mathrm{O}_{4}$ catalysts. These weakened interactions led to a lowering of the $\mathrm{Cu}$ particle embedment, coinciding with a pronounced $\mathrm{Cu}$ crystallite growth during reduction. Both effects partially compensate each other and a maximum in $\mathrm{Cu}$ surface area is observed for intermediate $\mathrm{Cr}$ contents. In the Ga-substituted catalysts, two distinct $\mathrm{Cu}$ species were found for high Ga contents. This is attributed to the presence of partially crystalline spinel and the resulting different strength of interface interaction of the $\mathrm{CuO}$ phase with the crystalline and the amorphous oxide. After reduction $\mathrm{Cu}$ catalysts with similar average $\mathrm{Cu}$ particle sizes as well as $\mathrm{Cu}$ surface areas were obtained. In both sample series, the catalytic activity in methanol synthesis does not scale with the $\mathrm{Cu}$ surface area and the experiments show that a strong interaction to the oxide is necessary to gain stability and activity of the $\mathrm{Cu}$ phase. Al substitution thus confirms that interface interactions between $\mathrm{Cu}$ and the oxide seem to beneficially affect the activity of the $\mathrm{Cu}$ particles and the optimal catalyst requires a compromise of exposed surface and interface.

\section{Introduction}

Besides ammonia and sulfuric acid, methanol belongs to the most important, industrially produced basic chemicals. It is considered as a potential substitute for traditional fuels, e.g. for the storage and generation of hydrogen for fuel cell applications [1,2]. Recently, around one-third of methanol is used in production of energy products [3]. For methanol production effective catalysts are necessary, which were investigated intensively over the last decades 
$[3,4]$. Nowadays, all catalysts used for the low-pressure methanol synthesis consist of copper and zinc oxide, and often alumina as stabilizing component [5, 6]. Mostly empirical optimization has led to a preparation route for the widely used $\mathrm{Cu} / \mathrm{ZnO} / \mathrm{Al}_{2} \mathrm{O}_{3}$ catalysts based on co-precipitation, followed by calcination and reduction [7, 8]. Cu, Zn,Al-hydrotalcite-like compounds (or layered double hydroxide - LDH) are a typical component of the precursor mixture of different hydroxycarbonates of the co-precipitation step in this synthesis $[9,10]$. Recently, $\mathrm{Cu}$-based catalysts obtained from $\mathrm{LDH}$ precursors were investigated in $\mathrm{CO}_{2}$ hydrogenation [11, 12] as well as low temperature shift reactions [13] and methanol oxidation [14]. In a previous study [15] we presented a Cu-based catalyst with a high intrinsic activity in methanol synthesis obtained from $\mathrm{Cu}, \mathrm{Zn}, \mathrm{Al} \mathrm{LDH}$ precursors. The hydrotalcite-like structure enables, furthermore, the insertion of a broad variety of cations, within a certain ionic size range and $\mathrm{M}(\mathrm{II}) / \mathrm{M}(\mathrm{III})$ ratio [16]. Thus, these materials can be seen as a precursor system representing a powerful basis to study the effect of different promoter species on the redox- and catalytic properties of the $\mathrm{Cu} / \mathrm{ZnO} / \mathrm{X}$ catalyst with the same $\mathrm{Cu}$ content and the same preparation history. Several multicomponent catalysts were described in literature, comprehensive overviews are given in [3] and [4].

Among first catalysts applied for methanol synthesis was $\mathrm{ZnO} / \mathrm{Cr}_{2} \mathrm{O}_{3}[17,18]$, which was replaced by the $\mathrm{Cu} / \mathrm{ZnO} / \mathrm{Al}_{2} \mathrm{O}_{3}$ catalyst in the 1960 s. Besides, Chromium oxide was used in ternary $\mathrm{Cu}$ based catalysts in industry in the early 1970s, e.g. BASF (German Patent 2,116,949) [19]. In 1996 Saito et al. presented multicomponent $\mathrm{Cu} / \mathrm{ZnO}$ based catalysts using $\mathrm{Cr}_{2} \mathrm{O}_{3}$ as well as $\mathrm{Ga}_{2} \mathrm{O}_{3}$ as ternary component [20]. Furthermore, $\mathrm{Ga}_{2} \mathrm{O}_{3}$ was reported as catalyst promotor by Fujitani et al. [21] and Toyir et al. [22]. In addition, studies presented in literature $[23,24,25,26]$ have already shown that it is possible to obtain LDH compounds with $\mathrm{Cr}$ and $\mathrm{Ga}$ as trivalent cation. Binary pure and well crystallized $\mathrm{Cu}, \mathrm{Cr} \mathrm{LDH}$ was prepared by Jiao et al. [25] with a molar ratio of $2: 1$. Venugopal et al. [23]described ternary $\mathrm{Cu} / \mathrm{Zn} / \mathrm{Cr}_{2} \mathrm{O}_{3}$ catalysts with a constant $\mathrm{Cu}$ content of $50 \mathrm{~mol} \%$ [23] as well as quaternary $\mathrm{Cu}, \mathrm{Zn}, \mathrm{Al}, \mathrm{Ga}$ catalysts [26], which were used for dimethyl ether synthesis. [26]Additionally, Nunan et al. [24] presented Cs-doped $\mathrm{Cu}, \mathrm{Zn}, \mathrm{X}(\mathrm{X}=\mathrm{Cr}, \mathrm{Ga})$ catalysts obtained from LDH. For $\mathrm{X}=\mathrm{Cr}$ the catalyst was characterized by very poor crystallinity and small crystallites. On the other hand, the $\mathrm{Cu}, \mathrm{Zn}, \mathrm{Ga}$ catalyst showed similar properties like an analogous $\mathrm{Cu}, \mathrm{Zn}, \mathrm{Al}$ catalyst. Anyway, it has to be mentioned, that nowadays chromium has mostly academic interests, e.g in CO oxidation studies [27] and is no longer used in industry due to its toxicity. 
$\mathrm{Al}$ in its oxidic form is thought to be a multifunctional promoter, which is working as a separator as well as an important species on the interface to $\mathrm{Cu}[28,29]$. Herein we present a systematic study, where $\mathrm{Al}$ is substituted stepwise by $\mathrm{Cr}$ and $\mathrm{Ga}$ to gain understanding of the functionality of $\mathrm{Al}$ within the $\mathrm{LDH}$-system as well as the resulting catalysts and to introduce new properties into the system. The general composition was always $\mathrm{Cu}: \mathrm{Zn}:(\mathrm{Al}+\mathrm{M})=50$ : $17: 33$, in which $\mathrm{Al}$ was substituted in $5 \%$ steps. The $\mathrm{Cu}, \mathrm{Zn}, \mathrm{Al} \mathrm{LDH}$ is the common origin of both the Cr- and Ga-sample series and was described in detail in our previous study [15].

\section{Material and Methods}

The $\mathrm{Cu}, \mathrm{Zn},(\mathrm{Al}), \mathrm{M}-\mathrm{LDH}$ precursors $(\mathrm{M}=\mathrm{Cr}, \mathrm{Ga})$ were precipitated from a mixed $\mathrm{Cu}^{2+} / \mathrm{Zn}^{2+} / \mathrm{Al}^{3+}+\mathrm{M}^{3+}$ nitrate solution with an aqueous solution of $\mathrm{NaOH}(0.3 \mathrm{M})$ and $\mathrm{Na}_{2} \mathrm{CO}_{3}$ $(0.045 \mathrm{M})$ as the precipitating agent (total metal concentration: $0.43 \mathrm{M}$ with $\mathrm{Cu}: \mathrm{Zn}$ : $(\mathrm{Al}+\mathrm{M})=50: 17: 33)$. The reaction was carried out at a constant $\mathrm{pH}$ value $(\mathrm{pH}=8 \pm 0.7)$ at $25^{\circ} \mathrm{C}-\mathrm{pH}$ and temperature were controlled by the automated lab reactor system (Labmax from Mettler Toledo). After an ageing time of one hour the blue powder was isolated by filtration, washing and drying at $100^{\circ} \mathrm{C}$ for $13 \mathrm{~h}$. Afterwards the sample was calcined in air at $330^{\circ} \mathrm{C}$ for $3 \mathrm{~h}$ (heating rate $2 \mathrm{~K} / \mathrm{min}$ ). Finally, the $\mathrm{Cu}$ based catalyst was obtained by reduction of the calcined sample in $5 \% \mathrm{H}_{2} /$ Argon and a heating rate of $6 \mathrm{~K} / \mathrm{min}$. The reduction temperature was adjusted for each catalyst to $15^{\circ} \mathrm{C}$ above $\mathrm{T}_{\max }$ of the TPR profiles.

The precursor sample without $\mathrm{Cr}$ or $\mathrm{Ga}$ is labeled as CZA, accordingly the calcined sample is labeled as CZA-calc and the reduced one as CZA-red. The $\mathrm{Cr}$ or Ga containing samples (A1 was substituted stepwise by $\mathrm{Cr}$ or $\mathrm{Ga}$ ) are labeled as $\mathrm{Cr} X$ and $\mathrm{Cr} X$-calc as well as $\mathrm{Ga} X$ and $\mathrm{Ga} X$-calc, respectively, where $X$ is the amount of $\mathrm{Cr}$ or $\mathrm{Ga}$ in at $\%$.

Methanol synthesis employing the calcined samples was carried out in a fixed bed micro reactor with an inner diameter of $2 \mathrm{~mm}$ filled with $180 \mathrm{mg}$ of the sieve fraction $(100-$ $200 \mu \mathrm{m}$. Prior to the activity measurements, the samples were activated by reduction in $\mathrm{H}_{2}$. The samples were first treated for $12 \mathrm{~h}$ in a mixture of $5 \% \mathrm{H}_{2}$ in $\mathrm{He}$ at $200^{\circ} \mathrm{C}$ using a heating rate of $0.3 \mathrm{~K} / \mathrm{min}$ and then for $4 \mathrm{~h}$ in pure $\mathrm{H}_{2}$ at $250^{\circ} \mathrm{C}$. Methanol synthesis was performed at total pressure of 60 bar. The synthesis gas was composed of $72 \% \mathrm{H}_{2}, 10 \% \mathrm{CO}, 4 \% \mathrm{CO}_{2}$ and balanced by He. Total flow was kept at $60 \mathrm{~mL} / \mathrm{min}$ by mass flow controllers. Methanol synthesis activity was measured under steady state conditions after $65 \mathrm{~h}$ at $250^{\circ} \mathrm{C}$ and $60 \mathrm{bar}$ by on-line GC analysis (Varian MicroGC 4900) equipped with a TCD using a PPU column, a $\mathrm{CO}_{\mathrm{x}}$ column, and a molsieve $5 \AA$ column for separating polar products, such as water, 
methanol, $\mathrm{CO}_{2}$ and $\mathrm{CO}$. After a formation period of ca. 12h, there is no major deactivation detectable in our experiments. Furthermore, no side products have been detected under these conditions, as the used syngas mixture contained $\mathrm{CO}_{2}$ and $\mathrm{CO}$ the selectivity towards methanol is $100 \%$. The methanol weight time yields (WTY) were calculated using the methanol concentration in the outlet gas and the uncertainty was estimated to $0.03 \mathrm{~g}_{\mathrm{MeOH}} \mathrm{g}_{\mathrm{Cat}}{ }^{-}$ ${ }^{1} \mathrm{~h}^{-1}$ on basis of reproduction experiments. The uncertainties of the relative WTYs (related to CZA-calc) as well as the intrinsic activities were calculated applying the rules for propagation of errors (Gauss).

All details for catalyst characterization as well as used materials can be found in SI.

\section{Results and Discussion}

\subsection{Microstructure of $\mathrm{Cr}$ and Ga containing LDH precursor and calcined samples}

For a detailed investigation of the effect of $\mathrm{Cr}$ and $\mathrm{Ga}$ on the $\mathrm{Cu}$ based catalysts, seven $\mathrm{Cr}$ containing and seven $\mathrm{Ga}$ containing samples were prepared and compared to the $\mathrm{Cu}, \mathrm{Zn}, \mathrm{Al}$ sample. The overall composition was $\mathrm{Cu}: \mathrm{Zn}:(\mathrm{Al}+\mathrm{M})=50: 17: 33(\mathrm{M}=\mathrm{Cr}, \mathrm{Ga})$, where Al was substituted in $5 \%$ steps. The XRF results in Table 1 (calcined samples measured) show that the composition is in good agreement with the nominal one used for preparing the starting solutions, especially regarding the herein interesting $\mathrm{Cr}$ and $\mathrm{Ga}$ contents. Unfortunately, in $\mathrm{Cr} 20$ the $\mathrm{Cu}$ content shows a quite high deviance from the nominal value. Furthermore, Cr33 still contains 1.6 at\% Al possibly due to cross-contamination. But this small amount of $\mathrm{Al}$ is considered as only a minor influence on the catalyst behavior.

Table 1: Metal contents in at $\%$ determined by XRF of calcined samples - top: Cr containing, bottom: Ga containing (nominal composition: $\mathrm{Cu}: \mathrm{Zn}:(\mathrm{Al}+\mathrm{M})=50: 17: 33)$; deviances for all samples: $\mathrm{Cu} \pm 0.08$ and $\mathrm{Zn} \pm 0.04$.

\begin{tabular}{lllllllll}
\hline & $\mathrm{CZA}$ & M5 & M10 & M15 & M20 & M25 & M30 & M33 \\
\hline $\mathrm{Cu}$ & 50.62 & 50.88 & 49.71 & 50.94 & 47.24 & 50.54 & 50.34 & 50.14 \\
$\mathrm{Zn}$ & 15.86 & 15.76 & 15.38 & 15.71 & 17.11 & 16.21 & 16.57 & 16.37 \\
$\mathrm{Al}$ & $33.5 \pm 0.4$ & $28.7 \pm 0.4$ & $25.6 \pm 0.3$ & $19.1 \pm 0.3$ & $15.2 \pm 0.3$ & $9.25 \pm 0.22$ & $4.2 \pm 0.2$ & $1.6 \pm 0.1$ \\
$\mathrm{Cr}$ & 0 & $4.7 \pm 0.1$ & $9.4 \pm 0.11$ & $14.3 \pm 0.1$ & $20.4 \pm 0.2$ & $24.0 \pm 0.2$ & $28.9 \pm 0.2$ & $31.9 \pm 0.19$ \\
\hline $\mathrm{Cu}$ & 50.62 & 49.29 & 51.33 & 50.90 & 51.30 & 51.64 & 51.80 & 51.33 \\
$\mathrm{Zn}$ & 15.86 & 15.32 & 16.23 & 16.32 & 16.33 & 15.74 & 16.44 & 16.54 \\
$\mathrm{Al}$ & $33.5 \pm 0.4$ & $30.5 \pm 0.3$ & $22.3 \pm 0.3$ & $17.4 \pm 0.3$ & $12.4 \pm 0.2$ & $7.3 \pm 0.2$ & $2.4 \pm 0.1$ & 0 \\
$\mathrm{Ga}$ & 0 & $4.84 \pm 0.01$ & $10.13 \pm 0.02$ & $15.42 \pm 0.02$ & $19.94 \pm 0.02$ & $25.35 \pm 0.02$ & $29.36 \pm 0.02$ & $32.13 \pm 0.02$ \\
\hline
\end{tabular}

The structural investigation by XRD, presented in Figure 1 indicates a hydrotalcite structure for all samples, showing a significant change of the pattern for $\mathrm{Cr}$ contents $\geq 15$ at $\%$ and an 
increasing crystallinity with increasing $\mathrm{Ga}$ content. By incorporation of $\mathrm{Cr}$ or $\mathrm{Ga}$ into the hydrotalcite lattice an increased $\mathrm{M}-\mathrm{M}$ distance is expected, as the ionic radius $\mathrm{of}^{3+}(0.615$ $\AA)$ and $\mathrm{Ga}^{3+}(0.62 \AA)$ are larger than the one of $\mathrm{Al}^{3+}(0.535 \AA)[30]$.

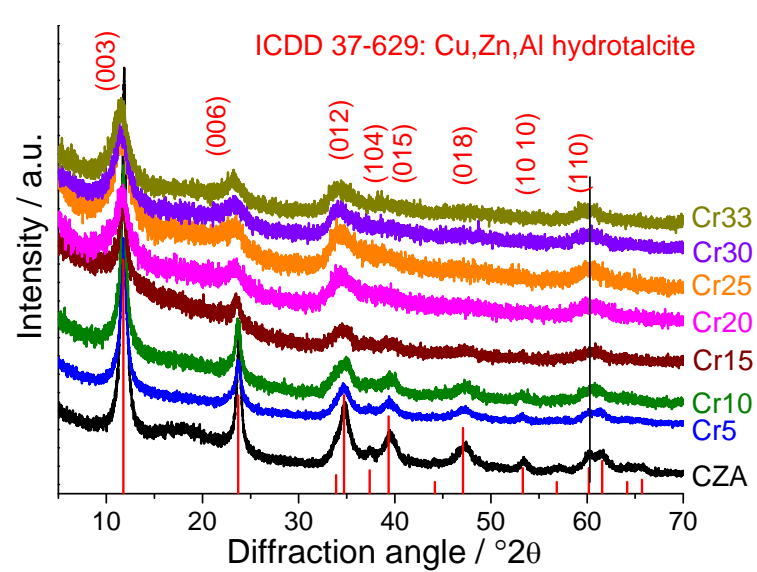

(a)

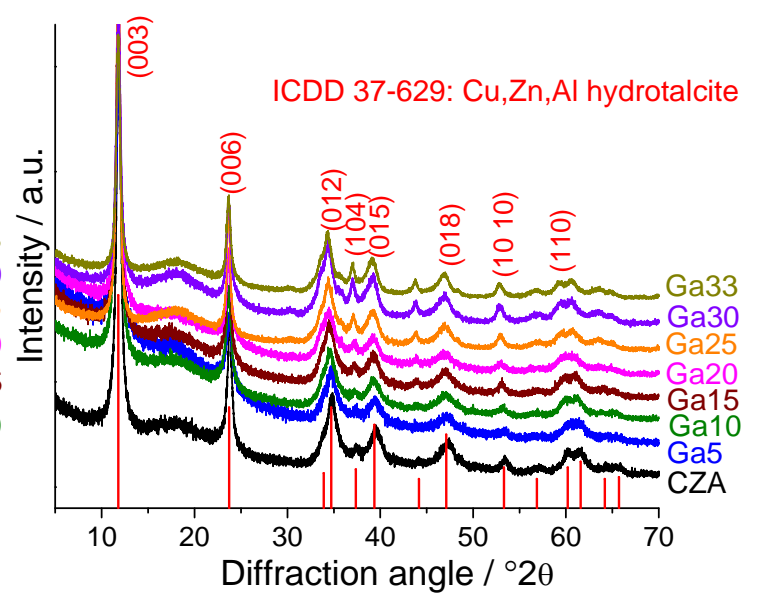

(b)

Figure 1: XRD patterns of precursors of (a) $\mathrm{Cr}$ and (b) Ga series in comparison to hydrotalcite-like structure.

The analysis of the peak position of the (110) reflection of $\mathrm{LDH}$, presented in Figure 2, shows an increased $d$-spacing for increasing Ga content. As this lattice plane is perpendicular to the brucite-like layers, this result proves an incorporation of Ga into the $\mathrm{LDH}$ structure.

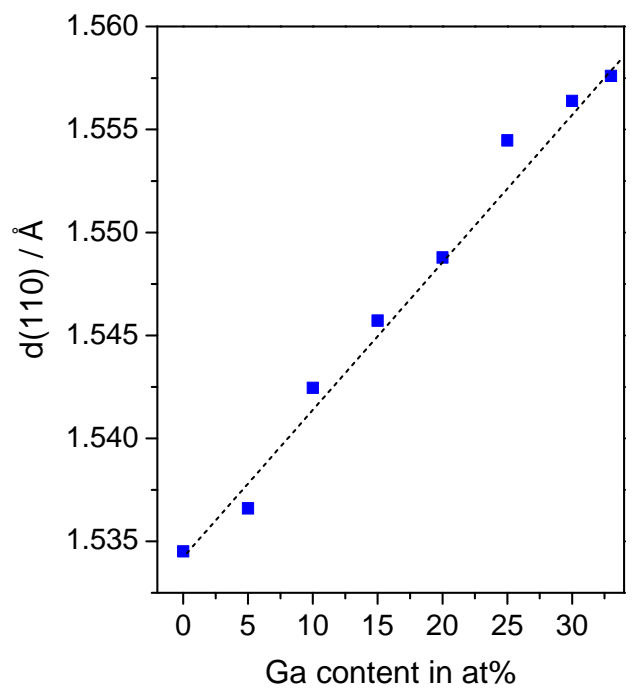

Figure 2: XRD of Ga series: peak analysis of (110) - indicating an increasing M-M distance.

In agreement with observations described in literature $[23,31]$ the crystallinity is decreasing with increasing $\mathrm{Cr}$ content. Therefore, a quantitative determination of the peak shift is not possible for the $\mathrm{Cr}$ series, but one can assume by visual comparison that the (110) reflection is shifted to lower angles or a larger $d$-spacing. Furthermore, as no other crystalline phase is observed the incorporation of $\mathrm{Cr}$ into the LDH structure is very likely, especially as Cr33 still shows the hydrotalcite structure. 
The average lateral particle size of the LDH platelets, which was determined from SEM images (see SI Fig. S1 for exemplary images), is $60-69 \mathrm{~nm}$ for small $\mathrm{Cr}$ contents $(\leq 10 \mathrm{at} \%$ ) and decreasing to $\approx 40 \mathrm{~nm}$ for higher $\mathrm{Cr}$ contents (see Tab. 2). This observation explains the apparently lower crystallinity manifested in the broader reflections (XRD) for higher $\mathrm{Cr}$ contents. As presented in Table 2, the BET surface area for the $\mathrm{Cr}$ containing samples is significantly higher than for CZA and a maximum is found for Cr15. All nitrogen adsorptiondesorption isotherms are presented in SI Figure S2.

On the other hand, the average platelet size (for exemplary SEM images see SI Fig. S1) is increasing (Tab. 2) with increasing Ga content. This is in agreement with the observed decreasing BET surface area (nitrogen adsorption-desorption isotherms presented in SI Fig. S3) and the increasing crystallinity observed by XRD.

Despite the similar size of $\mathrm{Ga}^{3+}$ and $\mathrm{Cr}^{3+}$, incorporation of $\mathrm{Ga}$ into $\mathrm{LDH}$ leads to an increased crystallinity with larger platelets whereas it is decreased with $\mathrm{Cr}$ insertion leading to smaller platelets. Accordingly, as also observed by Frost and Ding [31], the platelet size of LDH is determined by cation substitution, depending on the type of cation.

Table 2: Properties of precursors and calcined samples: average lateral particle sizes (PS) of precursor determined from SEM images (>150 platelets measured), BET surface areas (SA) of precursor $(\mathrm{M} X)$ and calcined $\left(\mathrm{M} X\right.$-calc) samples and decomposition temperature of $\mathrm{HT}-\mathrm{CO}_{3}{ }^{2-}\left(\mathrm{T}_{\mathrm{HT} \text {-carb }}\right)$.

\begin{tabular}{|c|c|c|c|c|c|c|c|c|}
\hline \multirow[b]{2}{*}{ at $\% M$} & \multicolumn{4}{|c|}{$\mathrm{M}=\mathrm{Cr}$} & \multicolumn{4}{|c|}{$\mathrm{M}=\mathrm{Ga}$} \\
\hline & $\begin{array}{l}\text { PS } \\
/ \mathrm{nm}\end{array}$ & $\begin{array}{l}\mathrm{SA}_{\mathrm{MX}} \\
/ \mathrm{m}^{2} \mathrm{~g}^{-1}\end{array}$ & $\begin{array}{l}\mathrm{SA}_{\mathrm{MX}-\mathrm{calc}} \\
/ \mathrm{m}^{2} \mathrm{~g}^{-1}\end{array}$ & $\begin{array}{l}\mathrm{T}_{\text {HT-carb }} \\
/{ }^{\circ} \mathrm{C}\end{array}$ & $\begin{array}{l}\text { PS } \\
/ \mathrm{nm}\end{array}$ & $\begin{array}{l}\mathrm{SA}_{\mathrm{MX}} \\
/ \mathrm{m}^{2} \mathrm{~g}^{-1}\end{array}$ & $\begin{array}{l}\mathrm{SA}_{\mathrm{MX} \text {-calc }} \\
/ \mathrm{m}^{2} \mathrm{~g}^{-1}\end{array}$ & $\begin{array}{l}\mathrm{T}_{\text {HT-carb }} \\
/{ }^{\circ} \mathrm{C}\end{array}$ \\
\hline 0 & 65 & 87 & 81 & 616 & 65 & 87 & 81 & 616 \\
\hline 5 & 69 & 128 & 109 & 540 & 61 & 84 & 64 & 597 \\
\hline 10 & 66 & 155 & 128 & 490 & 63 & 75 & 63 & 597 \\
\hline 15 & 60 & 186 & 135 & 480 & 70 & 66 & 60 & 598 \\
\hline 20 & 43 & 181 & 112 & 485 & 73 & 65 & 63 & 596 \\
\hline 25 & 43 & 161 & 108 & 470 & 82 & 67 & 59 & 603 \\
\hline 30 & 36 & 128 & 109 & 436 & 95 & 56 & 50 & 630 \\
\hline 33 & 39 & 118 & 85 & 420 & 99 & 43 & 42 & 629 \\
\hline
\end{tabular}

The investigation of the thermal behavior gives a first hint to the influences of $\mathrm{Cr}$ and $\mathrm{Ga}$ onto the LDH system. In Figure 3 the TG-MS curves of $\mathrm{Cr} 15$ and Ga15 are shown exemplarily (other TG diagrams can be found in SI Fig. S4-6). As observed for CZA [15], the decomposition of the $\mathrm{Cr}$ and $\mathrm{Ga}$ containing $\mathrm{LDH}$ samples is dominated by the decomposition of the hydrotalcite structure at low temperatures, meaning the emission of interlayer water at $125^{\circ} \mathrm{C}$ and the dehydroxylation and decarboxylation at $150-330^{\circ} \mathrm{C}$. All samples are, furthermore, characterized by a $\mathrm{CO}_{2}$ emission at higher temperatures $\left(>430^{\circ} \mathrm{C}\right)$ 


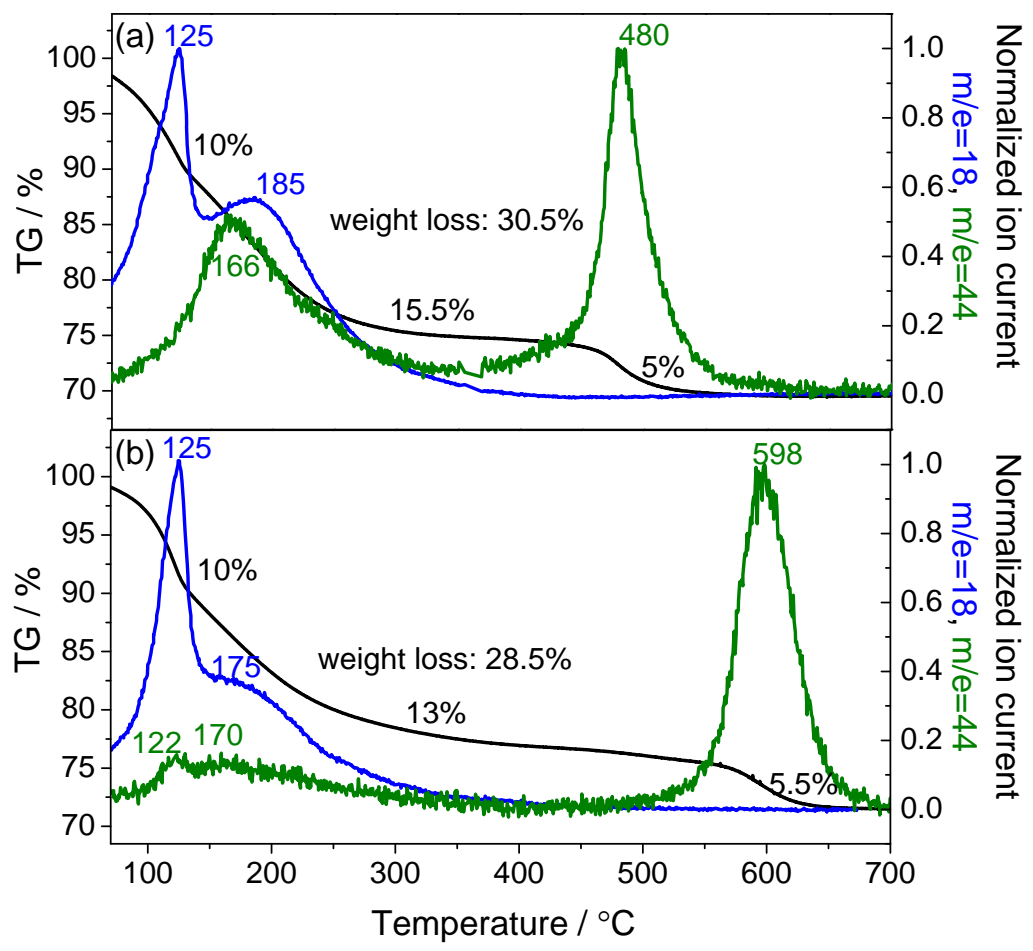

Figure 3: Weight loss and MS traces (blue $=\mathrm{H}_{2} \mathrm{O}$ and green $=\mathrm{CO}_{2}$ ) of substituted $\mathrm{LDH}$ compounds during heat treatment: (a) 15 at $\% \mathrm{Cr}$, (b) 15 at $\%$ Ga.

belonging to the decomposition of so-called high-temperature carbonate $\left(\mathrm{HT}_{-} \mathrm{CO}_{3}{ }^{2-}\right)[32,33$, 34], whose weight loss is constant with 5-6\%. As shown in Table 2 the decomposition temperature of $\mathrm{HT}-\mathrm{CO}_{3}{ }^{2-}$ significantly decreases with increasing $\mathrm{Cr}$ content with a local minimum at 15 at\% Cr. As already suggested elsewhere [35], a higher decomposition temperature is an indicator for strong interfaces and grain boundaries, which are formed during the first decomposition step and that can act as "traps" for carbonate anions. Accordingly, the lower thermal stability observed for the $\mathrm{Cr}$ containing hydrotalcite most probably results from a weaker interface contact of the $\mathrm{Cu}$ phase with the $\mathrm{Zn}-(\mathrm{Al}, \mathrm{Cr})$ matrix. Thus, Cr seems to loosen the microstructural stability of the mixed oxides resulting from LDH compounds.

In case of the Ga series, the overall weight loss is decreasing with increasing Ga content, which is in agreement with the higher theoretical weight loss due to the substitution of $\mathrm{Al}$ with the heavier homologue Ga. In contrast to the observation of the $\mathrm{Cr}$ series, the decomposition temperature of $\mathrm{HT}-\mathrm{CO}_{3}{ }^{2-}$ for the Ga containing samples (Tab. 2) is first decreasing (for Ga5), staying nearly constant for 5-20 at\% Ga and increasing again for higher Ga contents. But in general, the difference is much smaller than within the $\mathrm{Cr}$ series. With the assumption that this decomposition temperature correlates with the strength of 
interaction contact of $\mathrm{Cu}^{2+}$ with the $\mathrm{Zn}-\mathrm{X}$ matrix (see above), $\mathrm{Al}$ and $\mathrm{Ga}$ are quite similar, but substitution results in slightly smaller interface interaction for the quaternary samples.

For all samples the dehydroxylation and first decarboxylation, meaning the LDH decomposition, is finished before $330^{\circ} \mathrm{C}$. Thus, this temperature was chosen as calcination temperature. In the following, the calcined $\mathrm{HT}-\mathrm{CO}_{3}{ }^{2-}$ and $\mathrm{Cr}$ or $\mathrm{Ga}$ containing samples are labeled as $\mathrm{Cr} X$-calc and $\mathrm{Ga} X$-calc and the unsubstituted sample as CZA-calc. As shown in Figure 4(a) CZA-calc as well as $\mathrm{Cr} X$-calc are nearly x-ray amorphous mixed oxides, containing 7-8 wt $\%$ HT- $\mathrm{CO}_{3}{ }^{2-}$ (calculated from TG-MS curves). As shown in Figure 4(b) this is also valid for $\mathrm{Ga} X$-calc with $\leq 15 \mathrm{at} \% \mathrm{Ga}$, which contain $6-7 \mathrm{wt} \% \mathrm{HT}-\mathrm{CO}_{3}{ }^{2-}$. For higher $\mathrm{Ga}$ contents the formation of $\mathrm{ZnGa}_{2} \mathrm{O}_{4}$ spinel was observed, which is coinciding with an increasing decomposition temperature of $\mathrm{HT}-\mathrm{CO}_{3}{ }^{2-}$ (compare Tab. 2).

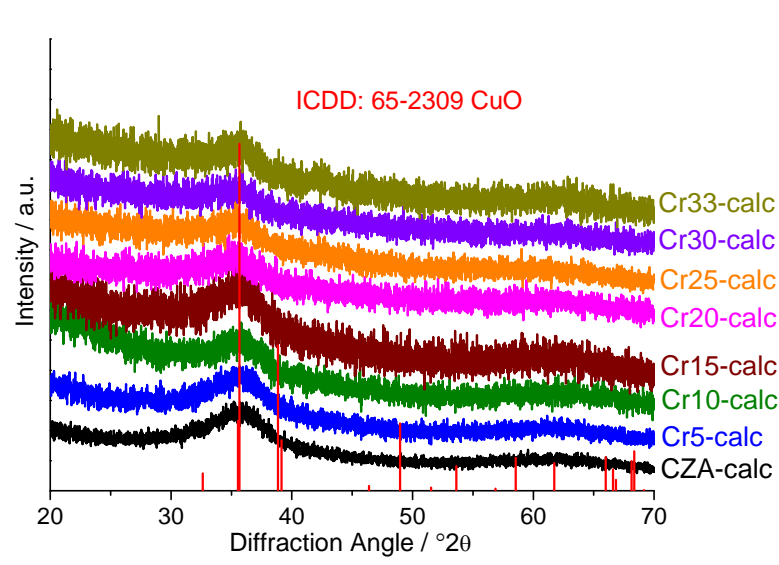

(a)

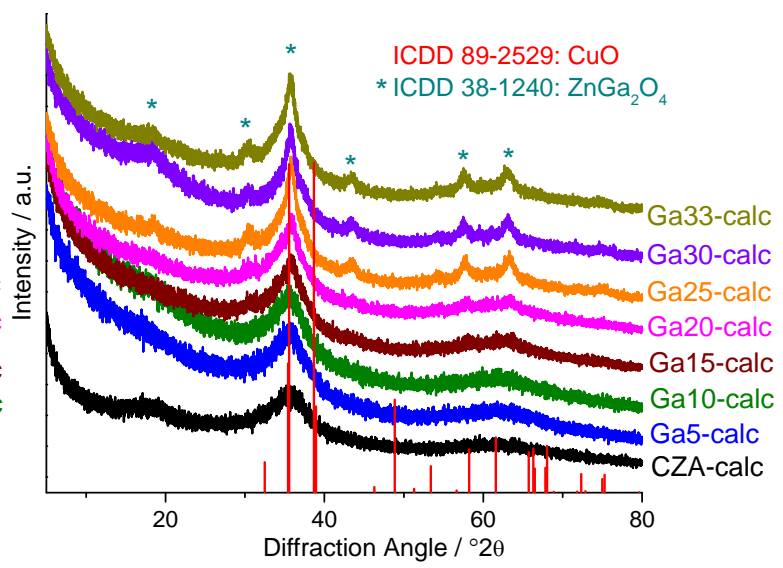

(b)

Figure 4: XRD patterns of (a) $\mathrm{Cr}$ and (b) Ga samples after calcination at $330^{\circ} \mathrm{C}$.

In case of CZA the spinel formation occurred more or less simultaneously with the decomposition of $\mathrm{HT}-\mathrm{CO}_{3}{ }^{2-}$ above $600^{\circ} \mathrm{C}$ [15]. The lower crystallization temperature of $\mathrm{Ga} X$-calc $(X \geq 20)$, especially of the spinel, indicates a phase separation during calcination at $330^{\circ} \mathrm{C}$, which was not observed for CZA-calc.

Thus, this sample series is handled as two groups of samples $-X<20$ and $X \geq 20$, a separation that is in agreement with the trends in BET surface area evolution (see Tab. 2) as well as the decomposition temperature of $\mathrm{HT}-\mathrm{CO}_{3}{ }^{2-}$.

For the $\mathrm{Cr}$ series the trend of the BET surface area is quite similar to the precursor samples, as the $\mathrm{Cr}$ containing samples have a higher surface area and again a maximum is obtained for 15 at\% $\mathrm{Cr}$ (Tab. 2). 


\subsection{Investigation of reduction behavior and microstructure of resulting catalysts}

The investigation of the reduction behavior of these sample series is based on the knowledge gained from the reduction of CZA-calc $[15,36]$. By complementary evaluation of TPR profiles and NEXAFS spectra during reduction [15], we have shown, that the intermediate $\mathrm{Cu}_{2} \mathrm{O}$ was kinetically stabilized due to a strong interaction of $\mathrm{Cu}$ and the $\mathrm{Zn}$ - $\mathrm{Al}$ matrix, resulting in the shoulder in the TPR profile of CZA-calc. As shown in Figure 5 the TPR profiles gradually change with the insertion of $\mathrm{Cr}$.

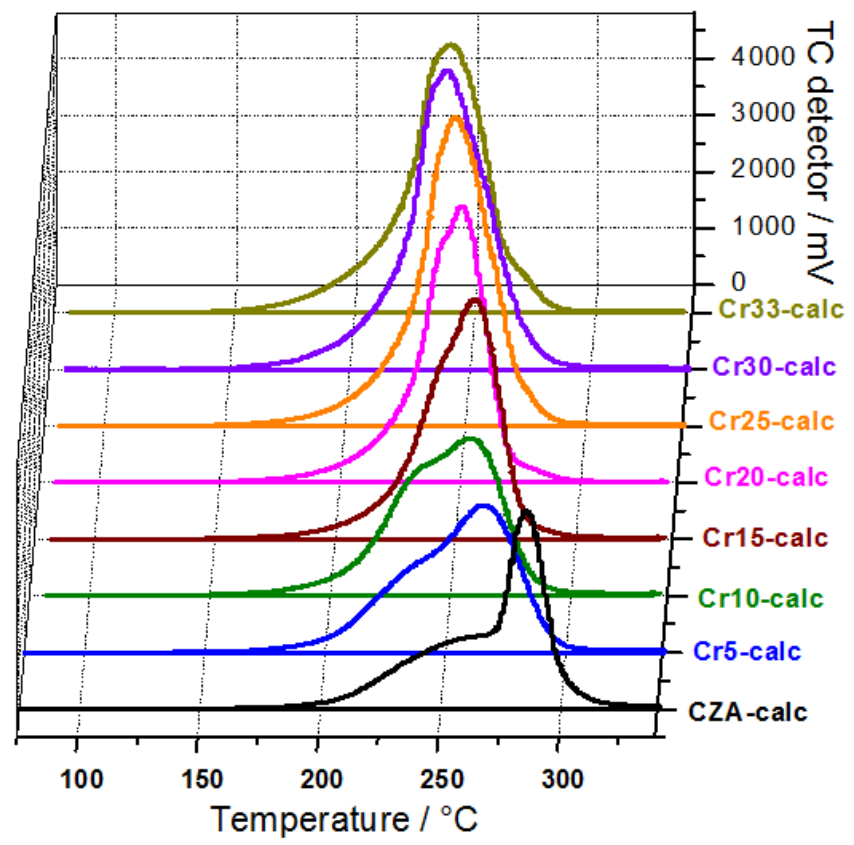

Figure 5: TPR profiles of $\mathrm{Cr} X$-calc samples (parameters set to $\mathrm{K}=106-108 \mathrm{~s}, \mathrm{P}=10.1-10.8 \mathrm{~K}$ ).

In agreement with the two groups of samples with $\mathrm{Cr} \leq 15$ at $\%$ and $\mathrm{Cr}>15$ at $\%$, already observed for the precursor samples (XRD, SEM and $\mathrm{N}_{2}$ physisorption), a big influence onto the reduction temperature (see Tab. 3) and mechanism can be observed. Within the group of small $\mathrm{Cr}$ contents $(\leq 15$ at $\%)$, the differences in the TPR profiles are much stronger compared to higher $\mathrm{Cr}$ concentrations.

As described in [15] for CZA-calc a high reduction temperature is caused by the required separation of reducible and irreducible species that is hindered by the homogeneous elemental distribution and the strong interaction of "CuO" with the $\mathrm{Zn}-\mathrm{Al}$ matrix, which has to be overcome before reduction. As was already indicated by TG-MS this interaction is weaker when $\mathrm{Cr}$ is present, and is further weakened with increasing $\mathrm{Cr}$ content. Hence, the lower reduction temperature is explicable by the weaker interaction.

Interestingly, the amount of consumed $\mathrm{H}_{2}$ (determined by calibration to commercial $\mathrm{CuO}$ Details on the calculation can be found in SI) relative to the amount of $\mathrm{CuO}$ present in the 
Table 3: TPR characteristics: temperature of highest reduction rate $\left(\mathrm{T}_{\max }\right)$ and hydrogen consumption in relation to present $\mathrm{CuO}$ (from XRF data - Tab. 1).

\begin{tabular}{llllllllll}
\hline \multirow{2}{*}{$\mathrm{at} \% \mathrm{M}$} & 0 & 5 & 10 & 15 & 20 & 25 & 30 & 33 \\
\hline \multirow{2}{*}{$\mathrm{Cr}$} & $\mathrm{T}_{\max } /{ }^{\circ} \mathrm{C}$ & 285 & 266 & 258 & 258 & 251 & 246 & 241 & 240 \\
& $\mathrm{H}_{2} / \mathrm{CuO} / \%$ & 98 & 105 & 113 & 118 & 138 & 142 & 147 & 150 \\
\hline \multirow{2}{*}{$\mathrm{Ga}$} & $\mathrm{T}_{\max } /{ }^{\circ} \mathrm{C}$ & 285 & 276 & 280 & 293 & 292 & 275 & 271 & 265 \\
& $\mathrm{H}_{2} / \mathrm{CuO} / \%$ & 98 & 98 & 96 & 99 & 99 & 98 & 97 & 96 \\
\hline
\end{tabular}

investigated catalysts (Tab. 3) is higher than $100 \%$ already for $\mathrm{Cr} 5$-calc and increases to $150 \%$ for $\mathrm{Cr} 33$-calc. This indicates that chromium oxide contributed to the hydrogen consumption and, thus, somehow plays an active role within the reduction process of the catalyst, which will be analyzed below.

Based on the two step reduction of $\mathrm{CuO}$ proved for CZA-calc [15], the qualitative peak deconvolution for the Cr containing samples, depicted in Figure 6 for $X=15$ and 33, shows two additional peaks. The assignment of the deconvoluted peaks was done by comparison of the experimental and stoichiometric hydrogen consumption under the assumption of a nearly complete reduction of $\mathrm{CuO}$, as observed for CZA-calc. Thus, the main peaks of the TPR signal belong to the $\mathrm{CuO}$ reduction and the additional reduction peaks are on the low and high temperature side of the main peaks. A more detailed explanation of the fitting procedure and additional fitting results, including a comparison to CZA-calc and the influence of heating rates are presented in SI (Fig. S8 and S10).

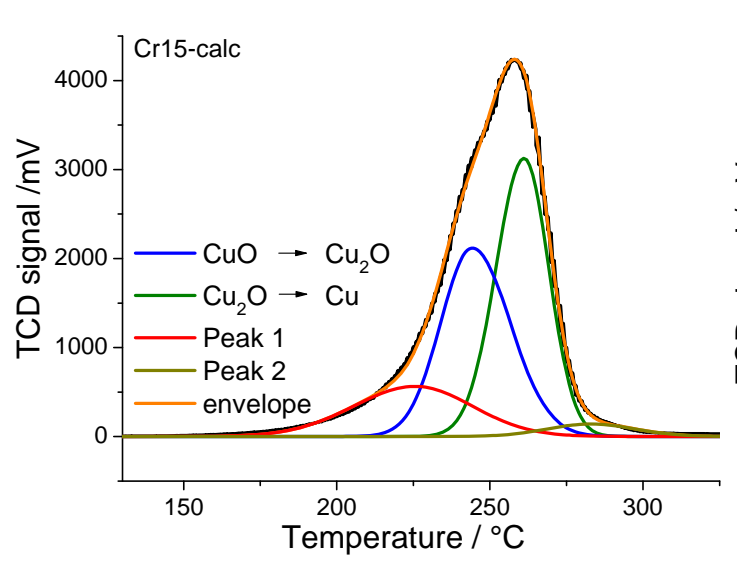

(a)

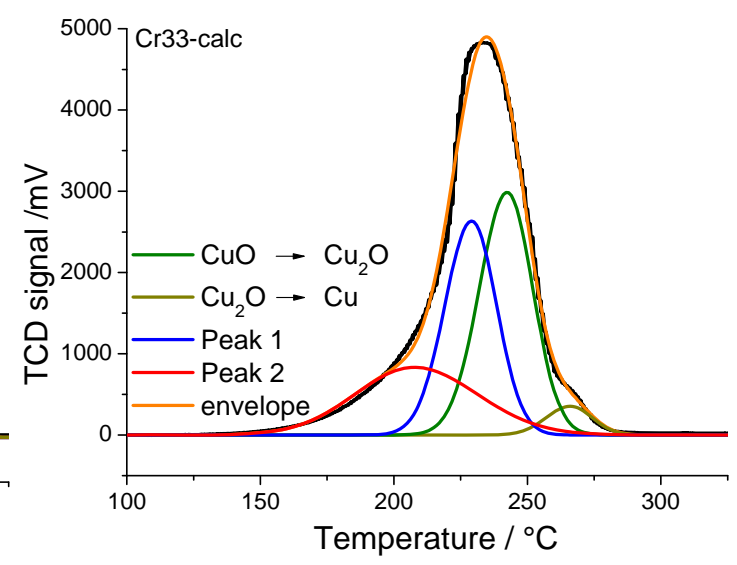

(b)

Figure 6: Peak deconvolution of TPR profiles: (a) Cr15-calc, (b) Cr33-calc.

There are several studies in literature reporting about $\mathrm{Cr}$ containing catalysts as well as the oxidation behavior of $\mathrm{Cr}_{2} \mathrm{O}_{3}$ upon calcination. For example, Apte et al. [37] reported about the conversion of $\mathrm{Cr}_{2} \mathrm{O}_{3}$ to hexavalent $\mathrm{Cr}$ (" $\mathrm{CrO}_{3}{ }^{\text {"“) }}$ ) when heated in the presence of oxygen at temperatures of $200-300^{\circ} \mathrm{C}$. Accordingly, for $\mathrm{Cr} X$-calc the formation of $\mathrm{Cr}(\mathrm{VI})$ seems to be likely, as they were obtained after calcination in air at $330^{\circ} \mathrm{C}$. The presence of $\mathrm{Cr}(\mathrm{VI})$ was 
also observed by Gaspar and Dieguez [38] by diffuse reflectance UV-vis spectroscopy in the calcined state of $\mathrm{Cr} / \mathrm{SiO}_{2}$ catalysts. Complete reduction to $\mathrm{Cr}_{2} \mathrm{O}_{3}$ by hydrogen required temperatures above $350^{\circ} \mathrm{C}$. Furthermore, Crivello et al. [39] investigated $\mathrm{Cr} / \mathrm{Cu} / \mathrm{Mg}$ mixed oxides derived from hydrotalcite-like compounds. By XPS they observed the presence of $\mathrm{Cr}^{6+}$ besides $\mathrm{Cr}^{3+}$ after calcination at $450^{\circ} \mathrm{C}$, whereas after reduction in hydrogen at $300^{\circ} \mathrm{C}$ only $\mathrm{Cr}^{3+}$ was found. To verify the presence of $\mathrm{Cr}^{6+}$ the $\mathrm{Cr}$ L-edge NEXAFS spectrum was measured of Cr33-calc (Fig. 7). By comparison to the spectrum of $\mathrm{Cr}_{2} \mathrm{O}_{3}$ as reference for $\mathrm{Cr}^{3+}$ and a NEXAFS study from literature [40] the peak at $580 \mathrm{eV}$ clearly proves the presence of $\mathrm{Cr}^{6+}$ besides $\mathrm{Cr}^{3+}$.

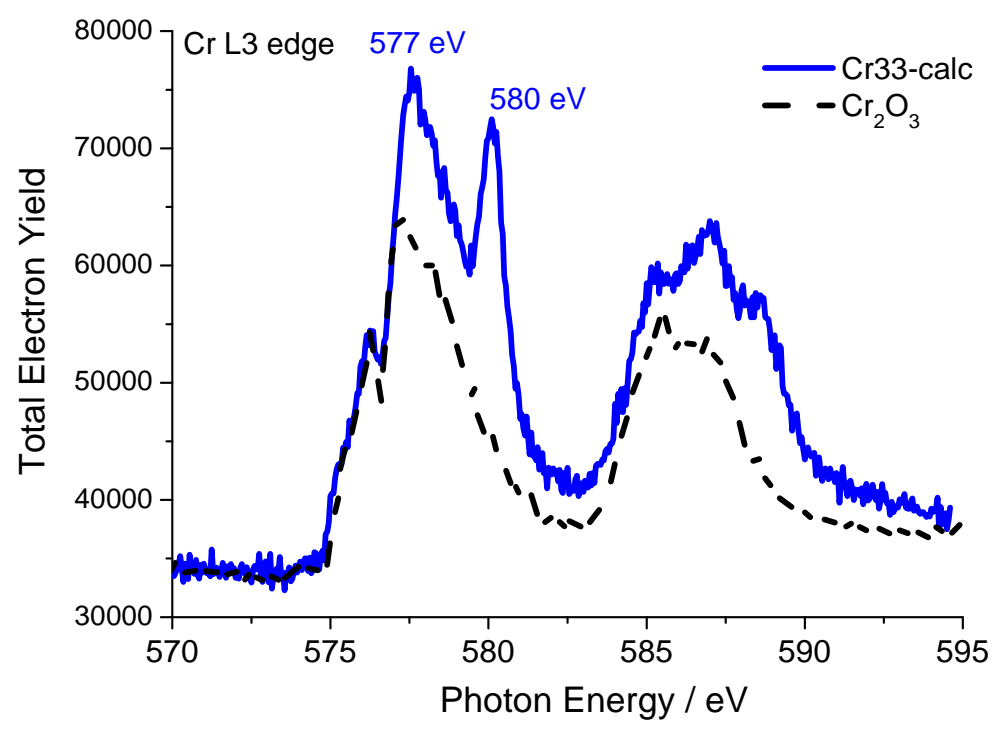

Figure 7: Cr L-edge NEXAFS spectra of $\mathrm{Cr} 33$-calc and $\mathrm{Cr}_{2} \mathrm{O}_{3}$ as reference for $\mathrm{Cr}^{3+}$.

Hence, $\mathrm{Cr}^{6+}$ is formed during the calcination of $\mathrm{LDH}$, i.e. before the decomposition of the high temperature carbonate. Thus, it may have also an impact on its thermal stability, which was shown to decrease with increasing $\mathrm{Cr}$ content (Tab. 2). Simultaneously, the interaction of $\mathrm{Cu}$ with the oxidic matrix is decreasing due to the Cr oxidation itself, resulting also in the lower reduction temperature. Accordingly, the redox process of chromium during catalyst preparation highly influences the $\mathrm{Cu}$ matrix interaction.

Based on these informations the additional reduction peak at the low temperature side of the $\mathrm{CuO}$ reduction (peak 1) is attributed to the reduction of $\mathrm{Cr}^{6+}$ represented by the reaction 2 " $\mathrm{CrO}_{3}$ " $+3 \mathrm{H}_{2}-\rightarrow \mathrm{Cr}_{2} \mathrm{O}_{3}+3 \mathrm{H}_{2} \mathrm{O}$. By comparison of the experimental and stoichiometric hydrogen consumption during reduction and assuming the complete reduction of $\mathrm{Cr}^{6+}$, it was possible to estimate the fraction of $\mathrm{Cr}^{6+}$ in all calcined catalysts to approximately $50 \%$ of the present Cr content, evaluated by XRF analysis (Tab. 1).

With regard to the high temperature reduction peak, Venugopal et al. [23] observed a single 
reduction peak at $325^{\circ} \mathrm{C}$ for a $\mathrm{ZnO} / \mathrm{Cr}_{2} \mathrm{O}_{3}$ catalyst which they proposed as the complete reduction of $\mathrm{Cr}_{2} \mathrm{O}_{3}$ finished at $350^{\circ} \mathrm{C}$. Accordingly, we assume this peak can be assigned to the reduction of $\mathrm{Cr}^{3+}$. The quantification of the deconvoluted peak allows for the estimation that in all samples 26 at $\%$ of $\mathrm{Cr}^{3+}$ were reduced to " $\mathrm{CrO}$ ".

Moreover, the peak deconvolution showed that the more $\mathrm{Cr}$ is present the less stable is the $\mathrm{Cu}_{2} \mathrm{O}$ intermediate (seen also from the vanishing shoulder of $\mathrm{CuO}$ reduction) which was observed as kinetically stabilized intermediate during the reduction of CZA-calc [15] caused by the strong interaction of $\mathrm{Cu}$ with the $\mathrm{Zn}-\mathrm{Al}$ matrix. Hence, this observation supports that the interaction of $\mathrm{Cu}$ and the $\mathrm{Zn}-\mathrm{X}$ matrix is weaker in the $\mathrm{Cr}$ containing samples. After all, a complete reduction of $\mathrm{CuO}$ accompanied by major changes within the oxide phase can be concluded from the TPR investigations.

With the insertion of Ga the TPR profiles gradually change as shown in Figure 8 .

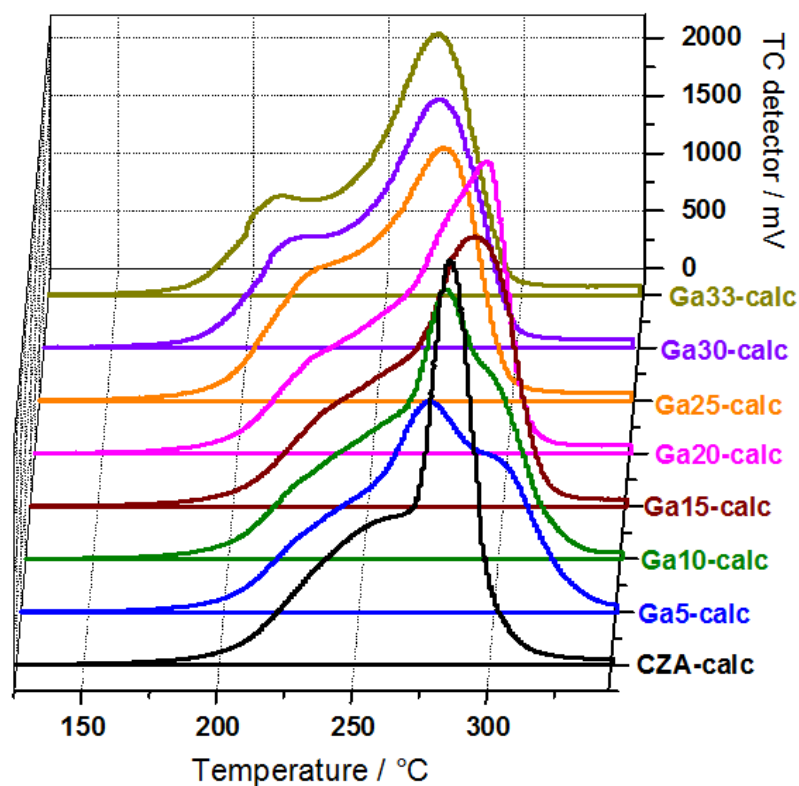

Figure 8: TPR profiles of GaX-calc samples (parameters set to $\mathrm{K}=105-109 \mathrm{~s}, \mathrm{P}=10.5-10.9 \mathrm{~K}$ ).

First of all, for low and high Ga content a decreased $\mathrm{T}_{\max }$ is observed compared to CZA-calc, whereas for $\mathrm{Ga}: \mathrm{Al}$ around 1 : 1 (Ga15-calc and Ga20-calc) a higher reduction temperature was found (see also Tab. 3). The observed changes of $T_{\max }$ are much smaller compared to the Cr-substituted sample series. Furthermore, the experimental hydrogen consumption is in agreement (Tab. 3) with the amount of $\mathrm{CuO}$ present in the samples, hence a direct participation of gallium oxide in the redox reaction, as observed for chromium oxide, can be excluded. Accordingly, all observed changes are due to $\mathrm{CuO}$ and its interaction with the $\mathrm{Zn}$ $(\mathrm{Al}, \mathrm{Ga})$ matrix. Based on the characterization of $\mathrm{Ga} X$-calc, the sample series is devided in two groups to analyze the reduction behavior $(X<20$ and $X \geq 20)$. As already seen in the $\mathrm{Cr}$ 
series a higher reduction temperature is caused by a strong interaction of " $\mathrm{CuO}$ " with the oxide matrix, which has to be overcome before reduction. The decomposition temperature of HT- $\mathrm{CO}_{3}{ }^{2-}$ upon calcination (see Tab. 2) has already indicated that the interaction is slightly weaker for the first group of samples (5-15 at\% Ga) compared to CZA-calc, which can explain the lower $\mathrm{T}_{\max }$ of Ga5-calc.

The increasing reduction temperature within this group, is probably due to a particle size effect implemented by the LDH precursor, similar to reports in [41, 42, 43]. All four samples have approximately the same decomposition temperature of $\mathrm{HT}-\mathrm{CO}_{3}{ }^{2-}$ but an increasing particle size was observed by SEM of the precursor samples (Tab. 2). Furthermore, the TPR profile of Ga5-calc and Ga10-calc show, additional to the well described shoulder on the low temperature side [15], a shoulder on the high temperature side. This is also illustrated within the qualitative peak deconvolution for Ga5-calc in Figure 9(a), which is based on the twostep reduction mechanism of $\mathrm{CuO}$ and the knowledge gained from the reduction of CZA-calc [15]. As this shoulder is not influenced when different heating rates are applied (results presented in SI Fig. S11), it can be excluded that this effect is caused by regions with different particle sizes [43]. Accordingly, the only explanation for this observation is that these samples contain two slightly different $\mathrm{Cu}$ species due to the modifications in the oxide matrix by substitution of $\mathrm{Al}$ by $\mathrm{Ga}$ which is changing the interaction of the $\mathrm{Cu}$ phase and the $\mathrm{Zn}-(\mathrm{Al}, \mathrm{Ga})$ matrix.

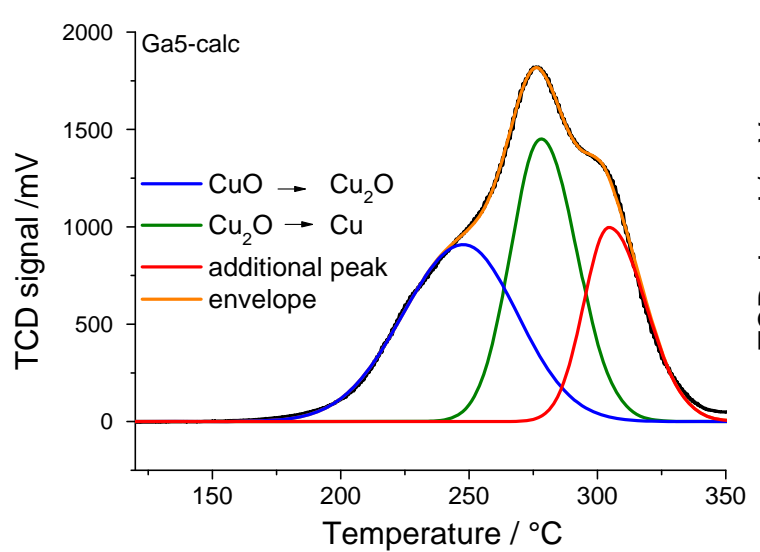

(a)

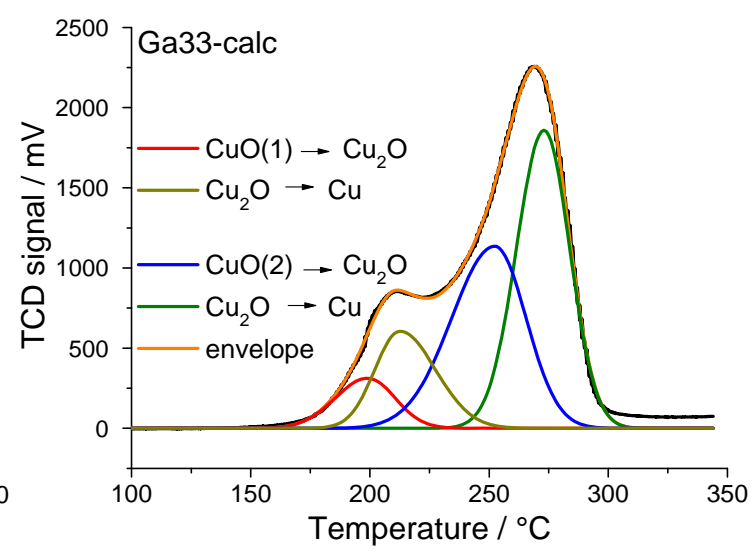

(b)

Figure 9: Peak deconvolution of TPR profiles: (a) Ga5-calc, (b) Ga33-calc.

On the other hand, the second group of this sample series (20-33 at $\% \mathrm{Ga})$ is characterized by an additional peak on the low temperature side, most pronounced for Ga33-calc (around $210^{\circ} \mathrm{C}$ ), indicating the presence of two different " $\mathrm{CuO}$ " species. This is also supported by the 
qualitative peak deconvolution, presented in Figure 9(b) (additional fitting results are presented in SI, S10).

Based on the knowledge gained from XRD of the calcined samples (Fig. 4(b)), the peak at lower temperatures is assigned to the weaker interaction of $\mathrm{Cu}^{2+}$ with the crystalline $\mathrm{Zn}(\mathrm{Al}, \mathrm{Ga})_{2} \mathrm{O}_{4}$ spinel. The high temperature peak is attributed to the stronger interaction of $\mathrm{Cu}^{2+}$ with the amorphous $\mathrm{Zn}-(\mathrm{Al}, \mathrm{Ga})$ matrix, as similar observed for CZA-calc [15]. Furthermore, the reduction temperatures is decreasing with increasing Ga content which is probably caused by the partial phase separation during calcination of these samples, seen by the formation of $\mathrm{ZnGa}_{2} \mathrm{O}_{4}$ besides the amorphous matrix.

Nevertheless, for Ga : Al around 1: 1 (Ga15-calc and Ga20-calc) a higher reduction temperature compared to CZA-calc was observed, as was noted above. This result shows that the ternary $\mathrm{Zn}-(\mathrm{Al}, \mathrm{Ga})$ oxide matrix can be very efficient in stabilizing the $\mathrm{CuO}$ phase against reduction compared to $\mathrm{Zn}-\mathrm{Al}$ or $\mathrm{Zn}-\mathrm{Ga}$ alone.

\subsection{Properties of resulting Cu catalysts and activity in methanol synthesis}

Traditionally, the $\mathrm{Cu}$ surface area was determined by $\mathrm{N}_{2} \mathrm{O}-\mathrm{RFC}$ [44]. According to recent findings [45, 46], where $\mathrm{N}_{2} \mathrm{O}$ chemisorption was compared to $\mathrm{H}_{2}$ chemisorption data, it is only possible to measure the chemisorption capacity of $\mathrm{N}_{2} \mathrm{O}$ and, thus, an apparent $\mathrm{Cu}$ surface area. Herein, the apparent $\mathrm{Cu}$ surface area of the obtained catalysts was determined for a selection of samples: $X=5,15,25,33$ (Tab. 4), where no influence was observed with substitution of $\mathrm{Al}$ by $\mathrm{Ga}$. Also the insertion of $\mathrm{Cr}$ had just slight influences on the $\mathrm{Cu}$ surface area, with a similar behavior as observed for the BET surface area as a maximum value results for Cr15-red.

Furthermore, the TEM investigation, exemplarily done for 15 and 33 at $\%$, showed in agreement to the $\mathrm{Cu}$ surface area nearly no influences on the $\mathrm{Cu}$ particle size with increasing Ga content (Tab. 4; images and PSD in SI Fig. S13 + S14(c,d)).

On the other hand an increasing $\mathrm{Cu}$ particle size was observed with increasing $\mathrm{Cr}$ content (Tab. 4; images and PSD in SI Fig. S12 + S14(a,b)). No pronounced loss of Cu surface area occur for the larger particles, as the particle growth is partially compensated with a lower interface ratio, i.e. the ratio of $\mathrm{Cu}$ surface inaccessible to the reaction gas but present as interface to the oxide phase (calculated from the experimentally measured $\mathrm{Cu}$ surface area and the average $\mathrm{Cu}$ particle diameter determined by TEM - details see SI). This lower embedment of the $\mathrm{Cu}$ particles in presence of $\mathrm{Cr}$ is explicable with the less strong interaction of $\mathrm{Cu}$ and the $\mathrm{Zn}-\mathrm{Cr}$ matrix in comparison to $\mathrm{Al}$. 
Table 4: Properties of catalysts after reduction: apparent $\mathrm{Cu}$ surface area (SA) deter- mined by $\mathrm{N}_{2} \mathrm{O}-\mathrm{RFC}$ and particle size (PS) by TEM particle size evaluation, interface ratio (IFR) is calculated from theoretic $\mathrm{Cu}$ surface area for free-standing $\mathrm{Cu}$ particles based on TEM particle size (n.m. = not measured).

\begin{tabular}{|c|c|c|c|c|c|c|}
\hline \multirow[b]{2}{*}{ at $\%$} & \multicolumn{3}{|c|}{$\mathrm{Cr}$} & \multicolumn{3}{|c|}{$\mathrm{Ga}$} \\
\hline & $\begin{array}{l}\mathrm{Cu} \text { SA } \\
/ \mathrm{m}^{2} / \mathrm{g}\end{array}$ & $\begin{array}{l}\mathrm{Cu}-\mathrm{PS} \\
/ \mathrm{nm}\end{array}$ & $\begin{array}{l}\text { IFR } \\
1 \%\end{array}$ & $\begin{array}{l}\mathrm{Cu} \text { SA } \\
/ \mathrm{m}^{2} / \mathrm{g}\end{array}$ & $\begin{array}{l}\mathrm{Cu}-\mathrm{PS} \\
/ \mathrm{nm}\end{array}$ & $\begin{array}{l}\text { IFR } \\
/ \%\end{array}$ \\
\hline 0 & $7.4 \pm 0.7$ & 7 & 85 & $7.4 \pm 0.7$ & 7 & 85 \\
\hline 5 & $9.0 \pm 0.7$ & n.m. & n.m. & $7.0 \pm 0.7$ & n.m. & n.m. \\
\hline 15 & $9.3 \pm 0.8$ & 14.2 & 61 & $7.2 \pm 0.7$ & 8.5 & 81 \\
\hline 25 & $6.4 \pm 0.6$ & n.m. & n.m. & $7.6 \pm 0.8$ & n.m. & n.m. \\
\hline 33 & $7.3 \pm 0.7$ & 24.1 & 43 & $7.9 \pm 0.8$ & 8.6 & 76 \\
\hline
\end{tabular}

All these characteristics are also reflected in the catalytic activity in methanol synthesis (Fig. 10). It has to be mentioned that the absolute activity of these ex-LDH catalysts is rather low in comparison to a commercial one, but as we have shown before they are superior in their intrinsic activity (activity normalized by $\mathrm{Cu}$ surface area) [15]. For the recent study the activity data are investigated for correlations to the structural information described before. However, within these series of samples no correlation of the catalytic activity with the exposed $\mathrm{Cu}$ surface (Tab. 4) could be observed, but two different phenomena can be described for $\mathrm{Cr}$ and $\mathrm{Ga}$ substitution.

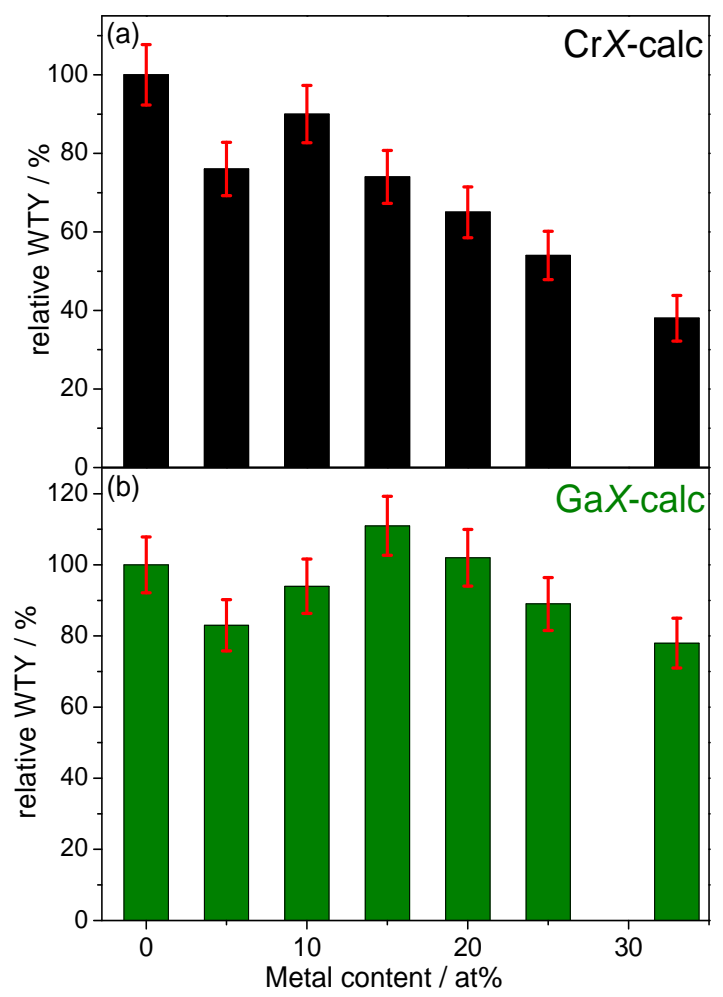

Figure 10: Activity in methanol synthesis at $250^{\circ} \mathrm{C}$ after $65 \mathrm{~h}$ TOS, normalized to CZA-red $(X=0)$; WTY = weight time yield of methanol $\left(\mathrm{kg}_{\mathrm{MeOH}} \mathrm{h}^{-1} \mathrm{~kg}_{\mathrm{cat}}{ }^{-1}\right)$ : results of (a) $\mathrm{Cr} X$-calc and (b) $\mathrm{Ga} X$-calc. The uncertainties of the relative WTYs (related to CZA-calc) were calculated applying the rules for propagation of errors (Gauss), based on the uncertainty of WTY (estimated to $0.03 \mathrm{~g}_{\mathrm{MeOH}} \mathrm{g}_{\mathrm{Cat}}{ }^{-1} \mathrm{~h}^{-1}$ by reproduction experiments). 
In case of the Cr containing catalysts (Fig. 10(a)), the activity is decreasing with increasing $\mathrm{Cr}$ content with the exception of $\mathrm{Cr} 5$-red. The catalytic properties can be nicely correlated with the observed decreasing strength of the interaction of $\mathrm{Cu}$ and the oxide matrix. Furthermore, the lower activity of Cr5-red compared to Cr10-red cannot be ignored as we already showed that the sample series is composed of two groups of samples. This suggests that two effects are competing for small Cr contents: the gradual changes by the stepwise substitution of $\mathrm{Al}$ by $\mathrm{Cr}$ and the significant changes in their precursor chemistry.

These results support the suggestion that $\mathrm{Cu}$ alone is not responsible for catalytic activity, but that also a special interaction to the oxide phase is required. Consequently, an increasing interface ratio results in an increasing intrinsic activity, as depicted in Figure 11(a) (circles). A converse correlation was observed for the increasing $\mathrm{Cu}$ particle size caused by the weaker interaction resulting in a lower intrinsic activity (Fig. 11(a), squares).

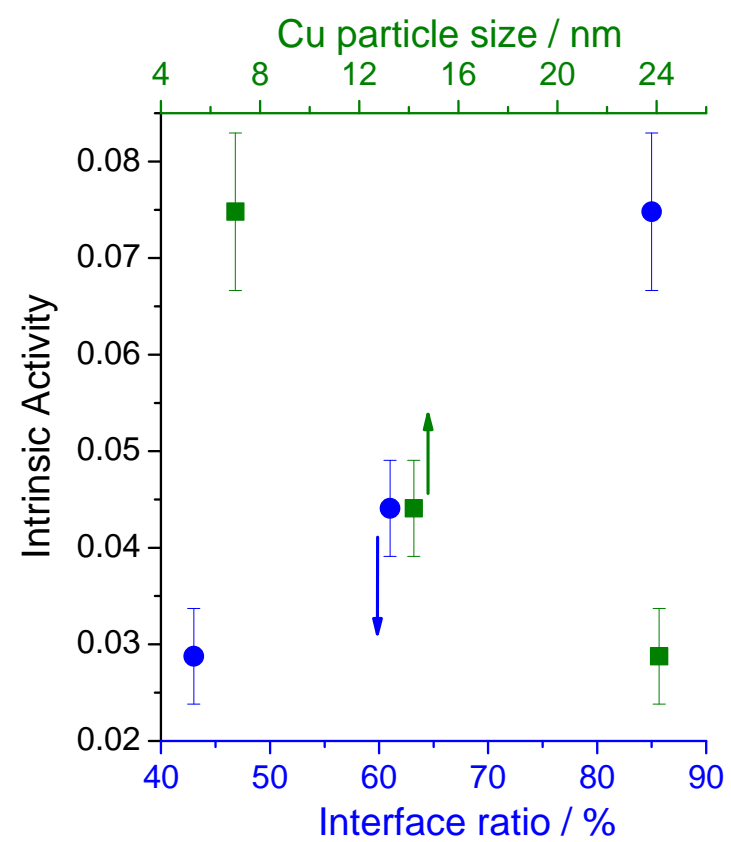

(a)

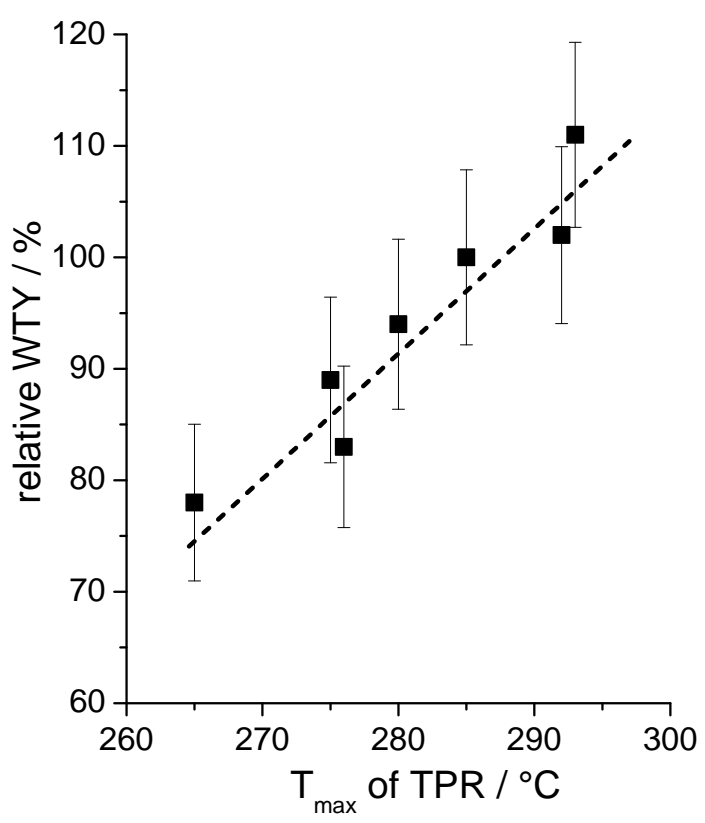

(b)

Figure 11: Comparison of catalytic activity in methanol synthesis: (a) Cr-series: intrinsic activity versus interface ratio and $\mathrm{Cu}$ particle size, (b) Ga-series: activity (relative to CZA) in dependence of $\mathrm{T}_{\max }$ of reduction of calcined samples (line is only guideline for the eye). The uncertainties of the relative WTYs (related to CZAcalc) as well as the intrinsic activities were calculated applying the rules for propagation of errors (Gauss), based on the uncertainty of WTY (estimated to $0.03 \mathrm{~g}_{\mathrm{MeOH}} \mathrm{g}_{\mathrm{Cat}}{ }^{-1} \mathrm{~h}^{-1}$ by reproduction experiments).

With introduction of $\mathrm{Ga}$ the changes of the activity are again much smaller than for the $\mathrm{Cr}$ series, as shown in Figure 10(b). Anyway, the lowest activity was found for 33 at $\%$ Ga, whereas the highest activity was observed for 15 and 20 at $\% \mathrm{Ga}$, where the $\mathrm{Al}$ : Ga ratio is around $1: 1$. In agreement with the stabilizing effect observed by TPR, this result shows that a ternary oxide can improve the intrinsic activity of $\mathrm{Cu}$ (illustrated in Fig. 
S16), if the general microstructure of the resulting catalyst is not influenced. On the other hand, the low activity of high Ga contents indicates that partially crystalline oxide, which is already present in the calcined state, yield a lower intrinsic activity of $\mathrm{Cu}$. Furthermore, in other studies it was shown, that the lower the reduction temperature during catalyst activation the higher is the activity of the derived catalyst [47, 48]. This sample series shows a more or less inverse trend: the higher $T_{\max }$ the higher is the activity in methanol synthesis (Fig. 11(b)). Thus, the reduction temperature is no direct indicator for the activity in methanol synthesis.

\section{Discussion and Conclusion}

First of all, the stepwise substitution of $\mathrm{Al}$ by $\mathrm{Cr}$ and $\mathrm{Ga}$ has shown that it is possible to systematically prepare quaternary LDH precursors for $\mathrm{Cu}$ based catalysts. The precursor characterization showed two families of samples for both series, each having significant different properties for small $\mathrm{Cr}$ or Ga contents $(\leq 15$ at $\%)$ compared to high contents. After decomposition in air carbonate-modified mixed oxides were obtained for $\mathrm{Cr}$ containing samples as well as for $\mathrm{Ga}$ contents $\leq 15$ at $\%$. Higher $\mathrm{Ga}$ contents led to the formation of crystalline $\mathrm{Zn}(\mathrm{Al}, \mathrm{Ga})_{2} \mathrm{O}_{4}$ or $\mathrm{ZnGa}_{2} \mathrm{O}_{4}$ spinel.

With the substitution of $\mathrm{Al}$ by $\mathrm{Cr}$ the special interaction of the $\mathrm{Cu}$ phase with the $\mathrm{Zn}-\mathrm{X}$ matrix is gradually weakened. This was indicated by a decreasing decomposition temperature of the high-temperature carbonate with increasing $\mathrm{Cr}$ content (TG-MS) and is caused by the participation of the chromium oxide phase at the redox processes during catalyst preparation, as shown by Cr NEXAFS and TPR investigations. Such reactive $\mathrm{Cr}$ oxide matrix is less efficient than the inert Al oxide matrix in stabilizing the special microstructure of $\mathrm{Cu} / \mathrm{ZnM}_{2} \mathrm{O}_{4}$ catalysts. It promotes the rearrangements in the solid state and does not hinder the $\mathrm{Cu}$ reduction as effectively as $\mathrm{ZnAl}_{2} \mathrm{O}_{4}$. These weakened interactions led to a lowering of the $\mathrm{Cu}$ particle embedment, coinciding with a pronounced $\mathrm{Cu}$ crystallite growth during reduction. Both effects partially compensate each other and a maximum in $\mathrm{Cu}$ surface area is observed for intermediate $\mathrm{Cr}$ contents. However, the catalytic activity does not scale with the $\mathrm{Cu}$ surface area in this series of samples, which is attributed to a difference in intrinsic activity of the exposed $\mathrm{Cu}$ surface in strong or weak interaction with the oxide matrix. Accordingly, this sample series shows nicely that a high interaction to the oxide is necessary to gain stability and activity of the $\mathrm{Cu}$ phase. Correlations of the intrinsic activities with decreasing $\mathrm{Cu}$ particle size and increasing interface ratio with the oxide 
component were found. These findings are in agreement with recent observations, that the intrinsic activity of $\mathrm{Cu}$ is related to defects and strain in the $\mathrm{Cu}$ particles $[49,50]$, which exhibit a larger concentration on small particles and are possibly "pinned" at the metal-oxide interface [51]. By the analysis of the TPR profiles of $\mathrm{GaX}$-calc two different $\mathrm{Cu}$ species were found for high Ga contents. This is attributed to the presence of partially crystalline spinel and the resulting different strength of interface interaction of the $\mathrm{CuO}$ phase with the crystalline and the amorphous oxide. The reduction of $\mathrm{GaX}$-calc led to $\mathrm{Cu}$ based catalysts with similar average $\mathrm{Cu}$ particle sizes as well as $\mathrm{Cu}$ surface areas and interface ratios. Similar to the $\mathrm{Cr}$ series, the small $\mathrm{Cu}$ particles are embedded within a $\mathrm{Zn}(\mathrm{Al}, \mathrm{Ga})_{2} \mathrm{O}_{4}$ spinellike matrix for $\mathrm{Ga}$ contents $\leq 15 \mathrm{at} \%$. For higher Ga contents the $\mathrm{Cu}$ particles are still highly embedded, but the oxidic matrix is also composed of crystalline $\mathrm{ZnGa}_{2} \mathrm{O}_{4}$ spinel. Their catalytic activity in methanol synthesis does not scale with the $\mathrm{Cu}$ surface area either but shows a maximum for intermediate $\mathrm{Ga}$ contents in those samples, where the Al-Ga substitution did not lead to a partial crystallization of the spinel ( $\mathrm{Ga}: \mathrm{Al} \approx 1: 1)$. Thus, it was shown that a ternary oxide has a stabilizing effect and is improving the intrinsic activity without significant influence onto the catalyst microstructure. On the other hand, the low activity of high $\mathrm{Ga}$ contents $(\geq 20$ at $\%$ ) indicates that an early phase separation (during calcination) and a partially crystalline oxide have a negative influence on the $\mathrm{Cu}$ matrix interaction resulting in a lower intrinsic activity.

After all, the Al substitution sample series show that it is possible to prepare series of $\mathrm{Cu}$ based catalysts with the same preparation history, which are characterized by a similar microstructure but significant differences in catalytic performance attributed to differences in intrinsic activity. This study confirms that interface interactions between $\mathrm{Cu}$ and the oxide seem to beneficially affect the activity of the $\mathrm{Cu}$ particles and the optimal catalyst requires a compromise of exposed surface and interface. The present investigation has shown that it is possible to tune the intrinsic activity of $\mathrm{Cu}$ in the resulting $\mathrm{Cu}$ based catalyst by modification of the interface area $(\mathrm{Cr})$ as well as the type of the interface interaction $(\mathrm{Ga})$.

\section{Acknowledgements}

We thank Robert Schlögl for his support and valuable discussions. Edith Kitzelmann, Achim KleinHoffmann as well as Gisela Weinberg are acknowledged for their supporting measurements and Clariant Produkte (Deutschland) $\mathrm{GmbH}$ for their continuous collaboration. This research was funded by the Bayerisches Wissenschaftsministerium (NW-0810-0002). 


\section{References}

[1] G.A. Olah, Angew. Chemie Int. Ed. 44 (18) (2005) 2636-2639.

[2] G.A. Olah, Angew. Chemie Int. Ed. 52 (1) (2013) 104-107.

[3] C.-H. Huang, C.-S. Tan, Aerosol and air quality research 14 (2) (2014) 480-499.

[4] N.A.M. Razali, K.T. Lee, S. Bhatia, A.R. Mohamed, Renewable Sustainable Energy Rev. 16 (7) (2012) $4951-4964$.

[5] P.J.A. Tijm, F. J. Waller, D. M. Brown, Appl. Catal. A: General 221 (2001) 275-282.

[6] J.B. Hansen, Methanol Synthesis, in Handbook of Heterogeneous Catalysis, Vol.6, 2nd Edition, Wiley-VCH, 2008, p. 2920-2949.

[7] M. S. Spencer, Top. Catal. 8 (1999) 259-266.

[8] D. Waller, D. Stirling, F. S. Stone, M. S. Spencer, Faraday Discuss. Chem. Soc. 87 (1989) 107.

[9] R. G. Herman, C. E. Bogdan, P. L. Kumler, D. M. Nuszkowski, Mater. Chem. Phys. 35 (1993) 233-239.

[10] R. H. Höppner, E. B. M. Doesburg, J. J. F. Scholten, Appl. Catal. 25 (1-2) (1986) 109-119.

[11] P. Gao, F. Li, F. Xiao, N. Zhao, W. Wei, L. Zhong, Y. Suna, Catal. Today 194 (1) (2012) 9-15.

[12] P. Gao, F. Li, H. Zhan, N. Zhao, F. Xiao, W. We, L. Zhong, H. Wang, Y. Sun, J. Catal. 298 (0) (2013) 51-60.

[13] M.M.V.M. Souza, K.A. Ferreira, O.R. de Macedo Neto, N.F.P. Ribeiro, M. Schmal, Catal. Today $133-135$ (0) (2008) $750-754$.

[14] M. Raciulete, G. Layrac, D. Tichit, I.-C. Marcu, Appl. Catal. A: General 477 (0) (2014) 195 204.

[15] S. Kühl, A. Tarasov, S. Zander, I. Kasatkin, M. Behrens, Chem. Eur. J. 20 (2014) 3782-3792.

[16] A. de Roy, Mol. Cryst. Liq. Cryst. 311 (1998) 173-193.

[17] D. R. Palo, R. A. Dagle, J. D. Holladay, Chem. Rev. 107 (2007) 3992-4021.

[18] K.-O. Hinrichsen, J. Strunk, Nachr. Chem. 54 (2006) 1080-1084.

[19] R.G. Herman, K. Klier, G.W. Simmons, B.P. Finn, J.B. Bulko, T.P. Kobylinski, J. Catal. 56 (3) (1979) $407-429$.

[20] M. Saito, T. Fujitani, M. Takeuchi, T. Watanabe, Appl. Catal. A: General 138 (1996) 311-318.

[21] T.Fujitani, M. Saito, Y. Kanai, M. Takeuchi, K. Moriya, T. Watanabe, M. Kawai, T. Kakumoto, Chem. Lett. 22 (6) (1993) 1079-1080.

[22] J. Toyir, P.R. de la Piscina, J.L.G. Fierro, N. Homs, Appl. Catal. B: Environmental 34 (4) (2001) $255-266$.

[23] A, Venugopal, J. Palgunadi, K. D. Jung, O.-S. Joo, C.-H. Shin, Catal. Lett. 123 (2008) 142-149.

[24] J. G. Nunan, P. B. Himelfarb, R. G. Herman, K. Klier, C. E. Bogdan, G. W. Simmons, Inorg. Chem. 28 (20) (1989) 3868-3874.

[25] Q. Jiao, H. Liu, Y. Zhao, Z. Zhang, J. Mater. Science 44 (2009) 4422-4428.

[26] A. Venugopal, J. Palgunadi, J. K. Deog, O. Joob, C. Shin, J. Mol. Catal. A: Chemical 302 (2009) 20-27.

[27] R. Prasad, P. Singh, Catal.Rev.: Science and Eng. 54 (2) (2012) 224-279.

[28] H. Wilmer, T. Genger, O. Hinrichsen, J. Catal. 215 (2003) 188-198. 
[29] M. Kurtz, H. Wilmer, T. Genger, O. Hinrichsen, M. Muhler, Catal. Lett. 86 (2003) 77-80.

[30] R. D. Shannon, Acta Cryst. Sec. A 32 (1976) 751-767.

[31] R.L. Frost, Z. Ding, Thermochimica Acta 405 (2003) 207-218.

[32] G. J. Millar, I. H. Holm, P. J. R. Uwins, J. Drennan, J. Chem. Soc., Faraday Trans. 94 (1998) 593-600.

[33] B. Bems, M. Schur, A. Dassenoy, H. Junkes, D. Herein, R. Schlögl, Chem. Eur. J. 9 (2003) 2039-2052.

[34] A. Tarasov, J. Schumann, F. Girgsdies, N. Thomas, M. Behrens, Thermochim. Acta (2014) doi:10.1016/j.tca.2014.04.025.

[35] M. Behrens, F. Girgsdies, A. Trunschke, R. Schlögl, Eur. J. Inorg. Chem. 10 (2009) 1347-1357.

[36] A. Tarasov, S. Kühl, J. Schumann, M. Behrens, High Temperatures-High Pressures 42 (2013) $377-386$.

[37] A. D. Apte, V. Tare, P. Bose, J. Hazard. Mater. B 128 (2006) 164-174.

[38] A. B. Gaspar, L. C. Dieguez, Appl. Catal. A: General 227 (2002) 241-254.

[39] M. Crivello, C. Pérez, J. Fernández, G. Eimer, E. Herrero, S. Casuscelli, E. RodríguezCastellón, Appl. Catal. A.: General 317 (2007) 11-19.

[40] D. Grolimund, T. P. Trainor, J. P. Fitts, T. Kendelewicz, P. Liu, S.A. Chambers, G.E. Brown, Jr., J. Synchrotron Rad. 6 (1999) 612-614.

[41] P. Panagiotopoulou, A. Christodoulakis, D.I. Kondarides, S. Boghosian, J. Catal. 240 (2) (2006) $114-125$.

[42] S.D. Robertson, B.D. McNicol, J.H. De Baas, S.C. Kloet, J.W. Jenkins, J. Catal. 37 (3) (1975) $424-431$.

[43] A. Jones, B. McNicol, Temperature-Programmed Reduction for solid materials characterization, Marcel Dekker, Inc. New York, Basel, 1986.

[44] G. C. Chinchen, C. M. Hay, H. D. Vandervell, K. C. Waugh, J. Catal. 103 (1987) 79-86.

[45] M. B. Fichtl, J. Schumann, M. Behrens, N. C. Jacobsen, M. Muhler, R. Schlögl, O. Hinrichsen, Angew. Chem. Int. Ed. 53 (2014) 7043-7047.

[46] S. Kuld, C. Conradsen, P. G. Moses, I. Chorkendorff, J. Sehested, Angew. Chem. Int. Ed. 53 (2014) $1-6$.

[47] G. Fierro, M. Lo Jacono, M. Inversi, P. Porta, F. Cioci, R. Lavecchia, Appl. Catal. A: General 137 (1996) 327-348.

[48] Y. Kawamura, K. Yamamoto, N. Ogura, T. Katsumata, A. Igarashi, J. Power Sources 150 (2005) 20-26.

[49] I. Kasatkin, P. Kurr, B. Kniep, A. Trunschke, R. Schlögl, Angew. Chem. 119 (2007) 74657468.

[50] M. M. Günter, T. Ressler, B. Bems, C. Büscher, T. Genger, O. Hinrichsen, M. Muhler, R. Schlögl, Catal. Lett. 71 (2001) 37-44.

[51] M. Behrens, A. Furche, I. Kasatkin, A. Trunschke, W. Busser, M. Muhler, B. Kniep, R. Fischer, R. Schlögl, ChemCatChem 2 (2010) 816-818. 